\title{
Relationship between Prior Knowledge and Reading Comprehension
}

\author{
Noureldin Mohamed Abdelaal (Corresponding author) \\ Faculty of Modern Languages and Communication \\ Universiti Putra Malaysia \\ E-mail: nourabdelal@yahoo.com \\ Amal Saleh Sase \\ Faculty of Modern Languages and Communication \\ Universiti Putra Malaysia \\ E-mail: saseamal@yahoo.com
}

Doi:10.7575/aiac.alls.v.5n.6p.125

Received: $17 / 08 / 2014$

URL: http://dx.doi.org/10.7575/aiac.alls.v.5n.6p.125

Accepted: 05/10/2014

\begin{abstract}
This study investigates the relationship between prior knowledge and reading comprehension in second language among postgraduate students in UPM. Participants in the study were 20 students who have the same level in English as a second language from several faculties. On the basis of a prior-knowledge questionnaire and test, students were selected; they were asked to sit a two-passage reading comprehension exam. According to the questionnaire and the short prior quiz, students had high prior knowledge in one of the two passages, and low prior knowledge in the other. The result showed significantly high relationship between the high prior knowledge and reading comprehension. However, the results showed significantly low relationship between low prior knowledge and reading comprehension. Yet the performance of students in a reading comprehension with high prior knowledge was significantly better than reading comprehension with low prior knowledge.
\end{abstract}

Keywords: reading; comprehension; prior knowledge; Universiti Putra Malaysia; postgraduate

\section{Introduction}

Reading is one of the main four skills of a language. It basically refers to the ability of decoding the graphemic string into spoken words. However this term is not used in such a simple way; it is used to refer to the ability to extract explicit and implicit meaning from the written text. The more you can understand and extract the meaning, the more you are competent at reading comprehension (Two, 2000). This comprehension of a reading requires that the reader being have comprehended the sentences, which depends on him has comprehended the clauses and phrases, which depends on him has comprehended the single words. In this sense reading is hierarchical. Others disagree and say reading skills are separable. The point here whether reading skill is hierarchical or separable is that the reading comprehension is the most important for reading. Reading comprehension is a complicated process because it involves different factors like vocabulary, fluency, culture, and familiarity with topic. Some scholars state that there is a relationship between reading comprehension and background knowledge. According to schema theory, you must have the prior knowledge to understand the meaning; for example, to think about the schema of a dog, you must have knowledge about dogs in general. To know that a dog is a four-leg animal which barks, bites...etc or you may need to have knowledge about some kinds of dogs. According to this theory, each new experience adds to your schema; in return such much knowledge or information will be about different thing and it will affect your reading comprehension. (Arbib, 1992) So schema or prior knowledge can play a part in reading comprehension. In spite of all that some other researchers disagree. For example, McNeil (2011) believes that prior knowledge does not play effective role for reading comprehension. He did a study on 20 university- level English language learners, but his results showed only $1 \%$ variance in favor of prior knowledge. So researchers disagree on whether prior knowledge is an effective contributor to better reading comprehension or not. In this study, we have two main variables; reading comprehension which is a dependent variable, and prior knowledge which is independent variable. Topic-relevant prior knowledge refers to readers' pre-existing knowledge related to the text content and can be assessed with open-ended and/or multiple choice questions on vocabulary and relevant factual information (Shapiro, 2004)

\subsection{Statement of the problem}

Different studies have dealt with how to increase reading comprehension, and different views and strategies were represented. Moreover, many researchers drew relationship between prior knowledge and reading comprehension. (Ozuru et al., 2009; Baldwin et al 1985; Walraven et al., 1993) all agreed that there is an impact of prior knowledge on reading comprehension. Shaprio (2004) states that prior knowledge has a strong impact on reading comprehension; 
such knowledge makes readers expect what is coming in the next lines, but it is important for a reader to have the correct prior knowledge because inaccurate knowledge about a topic can be misleading for the reader and has negative impact on the reader. On the other hand lack of such prior knowledge leads to difficulty in reading comprehension. But as a matter of fact, different studies gave different results. Carrell and Wise (1998) found that the effect of prior knowledge on reading comprehension is insignificant, while Chen (2008) found that there is statistically high significance of prior knowledge on reading comprehension. The researcher here did a study on 20 postgraduate students in UPM, to identify the relationship between prior knowledge and reading comprehension, and whether there is a significant relationship or not.

\subsection{Theoretical framework}

Reading is one of the important skills; however, students perform badly in reading, and find it difficult to understand a reading comprehension passage. This notion directed scholars to try to find the causes and solutions for the problem. Schema theory is the one which directed the attention to the constructive nature of the reading process, and also to the relationship between prior knowledge of a reader and his reading comprehension. It is noteworthy here to indicate that in L2 reading the two notions, prior knowledge and schema are used interchangeably (Nassaji, 2002). Anderson et al (1978) state that prior knowledge determines what a reader will learn from a text. Willingham (2007) also stresses that a reader relates what he knows to what he reads. Consequently schema theory has been highlighted by scholars.

Schema can be defined as cognitive knowledge stored in long term memory and gained through experience. There are three types of schemata; linguistic schemata which refers to proficiency of language in terms of grammar, vocabulary and idioms; formal schemata which include knowledge of different types of texts; content schemata which refers to the background knowledge of the content area of a text, or the topic a text talks about (Li et al., 2007). Peregoy and Boyle (2000) state that prior knowledge is important for native and nonnatives to achieve high level of comprehension.

To sum up, many scholars agree on the strong relationship between schema or prior knowledge and reading comprehension, and they find it important to activate the correct prior knowledge to make the reading task easier for readers. The following framework summarizes the relationship between prior knowledge, reading comprehension, and schema theory.

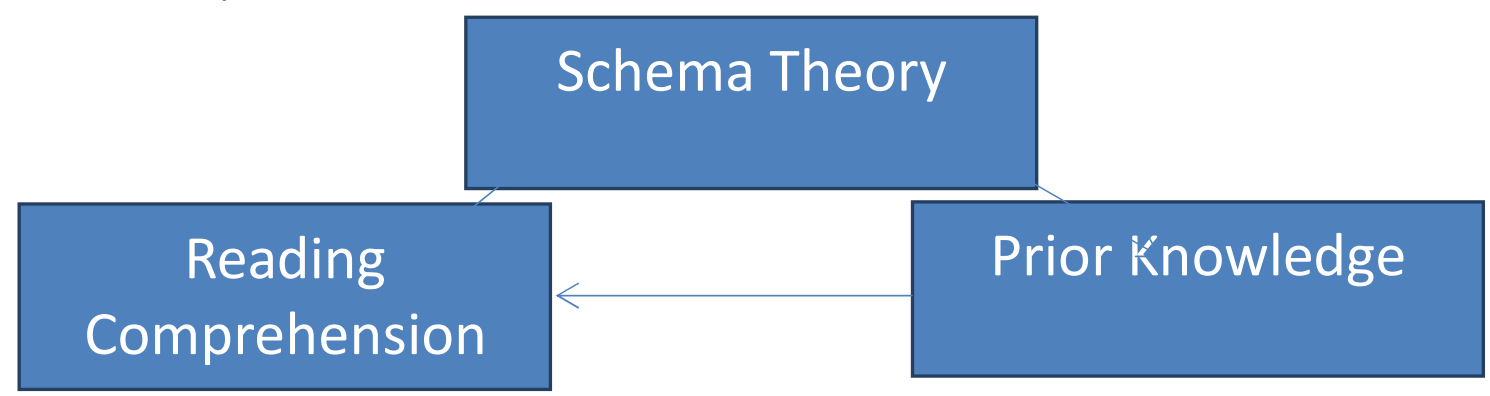

Figure 1. Relationship between prior knowledge, reading comprehension, and schema theory

\subsection{Objectives}

This study

1. investigates the relationship between high prior knowledge and reading comprehension among 20 UPM postgraduate students.

2. investigates the relationship between low prior knowledge and reading comprehension among 20 UPM postgraduate students.

\section{Literature Review}

Reading is one of the important skills; although some scholars disagreed on whether it is a skill or not. Yet there is a strong tendency for it to be considered as a skill. According to Hudson (2007), there are two main theories concerning reading skills. One sees skills as separable. The other one looks at skills as hierarchical. But it is no question that when we talk about reading as a skill, we mean reading comprehension. Why do different peoples have different levels of text comprehension? First let's give a definition for the term "comprehension". Reading comprehension means the ability to use context and knowledge to derive meaning from what is read like grammatical competence, knowledge of morphology, syntax, gaining meaning out of context, using schemata and metacognitive knowledge, recognizing text structure, and predicting what will come next in a text (Hudson, 2007)

Different researchers tackled the strategies which can be used to increase reading comprehension. Repeated reading can increase reading comprehension and fluency. It is tested that students who repeat reading can improve better on the level of fluency and comprehension. (Therrien, 2004) Repetition is a kind of prior knowledge because the student gets exposed to the text many times.

Other researchers state that teaching students the strategies of reading comprehension can increase their ability to comprehend texts. It's noted that poor readers when taught the strategies of reading comprehension and with the use of their prior knowledge improve better. (Walraven et al., 1993). It is argued that there is a relationship between reading comprehension and prior knowledge. Many researchers agree that prior knowledge effectively increases reading 
comprehension although it sometimes in certain texts it creates a kind of biasness (Johnston, 1984). Prior knowledge is important in creating a kind of interest, or may be sometimes such interest creates a kind of prior knowledge; anyhow such a kind of prior knowledge increases students' ability of comprehension (Baldwin et al., 1985). According to Baldwin (ibid.), students performed better when they read about something they have prior knowledge and interest, both of prior knowledge and interest have additive effects on reading comprehension, although they noticed is not that high. Prior knowledge increases reading comprehension by giving an immediate and effortless access to some information which is not clear or even missed out, and to relate ideas together. Such a prior knowledge facilitates our ability to predict to read fluently; and henceforth, to comprehend better (Ozuru et al., 2009).

In fact, many researchers agree on the importance of prior knowledge in facilitating reading comprehension although different studies showed different results. For example Ozuru et al., (2009) found that prior knowledge is more significant factor than reading skill on reading comprehension. While Baldwin et al (1985) showed that there is an effect of prior knowledge on reading comprehension but not that big one. Carrell and Wise (1998) also found that the effect of prior knowledge on reading comprehension is insignificant. The prior knowledge did not statistically show significance. Difference between high and low prior knowledge was only .25 (the difference between $\mathrm{M}=6.23$ and $\mathrm{M}=$ 5.98) on an 11-point scale (0-10). On the other hand Chen (2008) in his $\mathrm{PhD}$ thesis found that there is statistically high significance of prior knowledge on reading comprehension. The mean scores of students who were given the chance of previewing the target passage and who are culturally familiar with the reading passage at times 1 and 2 , were 9.70 and 9.35 respectively. On the other hand those students who were not provided preview or given a culturally familiar reading passage were 6.75 and 5.85 at times 1 and 2 respectively.

\subsection{Conceptual framework}



Figure 2. Conceptual framework

This figure shows the relationship between the two variables of the study; the independent variable which is prior knowledge, and the dependent variable which is reading comprehension.

\section{Methodology}

\subsection{Research design}

This study is a quantitative study because it explains a phenomenon by collecting numerical data that are analyzed using mathematically based methods (as it will be explained later on).

3.2 Design of the study

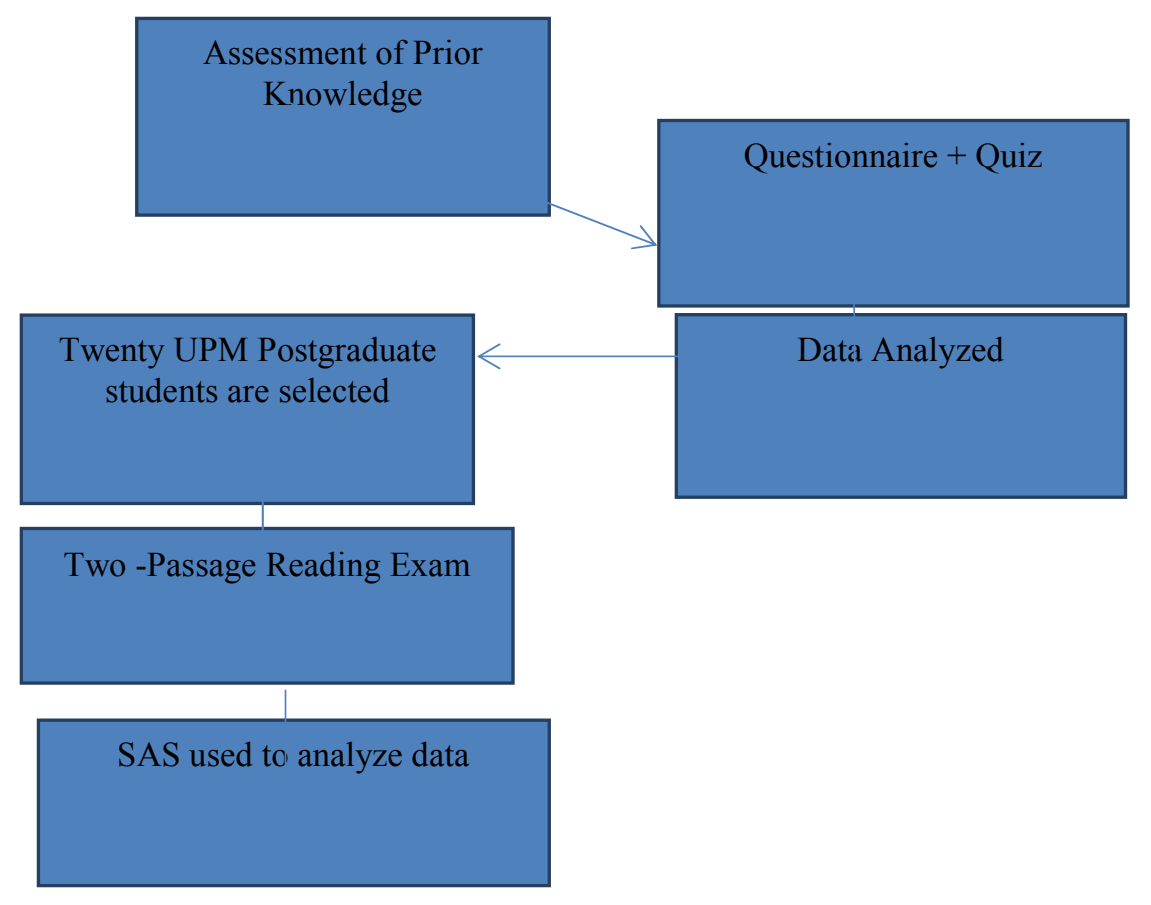

Figure 3. Design of Study

As the figure shows, the first step of the study was to select students of the same language standard, and with the same high and low prior knowledge. For that purpose students were selected according to their IELTS score, and to assess prior knowledge, 50 students were asked to fill out a questionnaire and do a short quiz. Out of the fifty students, twenty 
students were selected, and they were asked to sit a reading exam. The exam papers were scored, and then statistically analyzed using SAS.

\subsection{Participants}

Participants were 20 students from UPM; they were students from different colleges doing a master degree in different areas. They were selected according to their IELTS score; the selected students' scores ranged from 6 to 6.5 . According to IELTS website "Band 6" reflects a competent user who has generally effective command of the language despite some inaccuracies, inappropriacies and misunderstandings, can use and understand fairly complex language, particularly in familiar situations. 6.5 is not from 6 , especially when we take in consideration the probability of repeating the test. The resulting sample was 20 students; 12 males and 8 females. Some students were excluded like those who are from the faculty of agriculture because of their high familiarity with both of the two topics

Students had to sign a consent document to show their ability to take part in the questionnaire and the two-reading passage exam.

Table 1. Participants by proficiency level

\begin{tabular}{llll}
\hline Proficiency level & Gender $(\mathrm{M})$ & Gender $(\mathrm{F})$ & Total \\
\hline 6 & 10 & 6 & 16 \\
6.5 & 2 & 2 & 4 \\
\hline
\end{tabular}

\subsection{Materials and methods}

Topic selection and source of texts

Subjects were assessed on different components of reading comprehension; the passages were selected according to a questionnaire which showed high interest and prior knowledge in computers and cellphones $(\mathrm{M}=9)$. On the other hand the questionnaire and quiz showed low interest and prior knowledge in insects and bees $(\mathrm{M}=3.8)$.

The passages were quantitatively at the same level as they were selected from ReadWorks.Org; both of the two texts were at the same Lexile Level $(1350 \mathrm{~L})$. Based on the questionnaire, the following passages were selected (the passages are at the same Lexile Level which means that they are at the same difficulty level:

\section{Worldwide Loss of Bees a Growing Concern}

2. Using cellphones and computers to transmit information

The two texts were written by Alissa Fleck; this may also give more reliability of the difficulty level of the texts. . The Lexile Framework for Reading is an educational tool that uses a measure to match readers of all ages with books, articles and other leveled reading resources. The Lexile Framework uses quantitative methods, based on individual words and sentence lengths, rather than qualitative analysis of content to produce scores. It is valid, reliable, and had excellent psychometric properties (Mesmer, 2007).

\subsection{Procedures}

\subsubsection{Assessment of prior knowledge}

According to the literature, prior knowledge is constituted by two main constructs: domain and topic knowledge. Moreover the construct of topic knowledge can be divided in two subcomponents to describe the growth of understanding: knowledge of facts and knowledge of meanings. . A questionnaire and a quiz were used to assess prior knowledge; this questionnaire consisted of multiple choice questions ( 8 items), and two open-ended questions; this method was used because the literature on prior knowledge and reading comprehension demonstrated how results can be affected by the assessment method implemented (Dochy, 1992; Dochy et al., 1999). The test was a supplement of the questionnaire, so students did the questionnaire and answered the test at the same time. Fifty students were given the questionnaire, and only twenty were selected. The quiz was used to deeply assess their prior knowledge. The quiz then was graded and students were given scores. Scores reflected their high prior knowledge in the 'Using cellphones and computers to transmit information' passage

\subsubsection{Two-passage reading exam}

Subjects of the study were asked to sit a two -passage reading exam . The exam results were analyzed statistically to show the significance of the relationship between high prior knowledge and reading comprehension, and the relationship between low prior knowledge and reading comprehension.

\subsubsection{Data analysis}

Data was analyzed by T-test using SAS. The high and low prior knowledge scores (quiz scores) were correlated with the reading comprehension scores of the high and low prior knowledge reading passages, respectively. T-test using Excel was used to compare the scores of the two reading passages

\section{Findings}

The first objective of the study was to show the relationship between prior knowledge and reading comprehension. Similar to the findings of (Arbib, 1992), Shaprio (2004), and Chen (2008), this study reflected a strong significant relationship between prior knowledge and reading comprehension.

Reading performance score and background knowledge of the topic were significantly related. Their reading performance score is low when the amount of background knowledge decreases. That's is to say, students get the 
highest grade in the part of the exam whose reading text serves for the highest amount of background knowledge, while they get the lowest grade in the reading passage with the lowest background amount

As the results showed, the subjects scored best in the test of the most familiar topic since they grasped the greatest amount of background knowledge. As (Bransford et al., 1973; Kintsch et al., 1975; Adams \& Bruce, p. 37, 1980) explained why prior knowledge is important; it makes the text clearer, and makes the reader fill the missing gap of information, and without such prior knowledge text may sound difficult to understand.

Carrell (1987) delivered an explanation for the case by stating that unfamiliar topics make it difficult to infer meaning. That outcome is highly related to the present study which showed that the lowest grade was associated with the unfamiliar topic.

Besides, among the three schemata, content schema labeled as the best indicator of text comprehension because with the use of appropriate schemata, the reader determines the important and relevant aspects of a text by excluding the secondary ones within text processing criteria, generating hypothesis for the gaps in comprehension and recalling them when it is necessary (Gilakjani and Ahmadi, 2011). Therefore, if there is not appropriate background knowledge, the reader cannot make sense well of what he is reading. Apart from all these, background knowledge is necessary to overcome the language difficulties during the comprehension process.

Table 2. Correlation between prior knowledge and reading comprehension

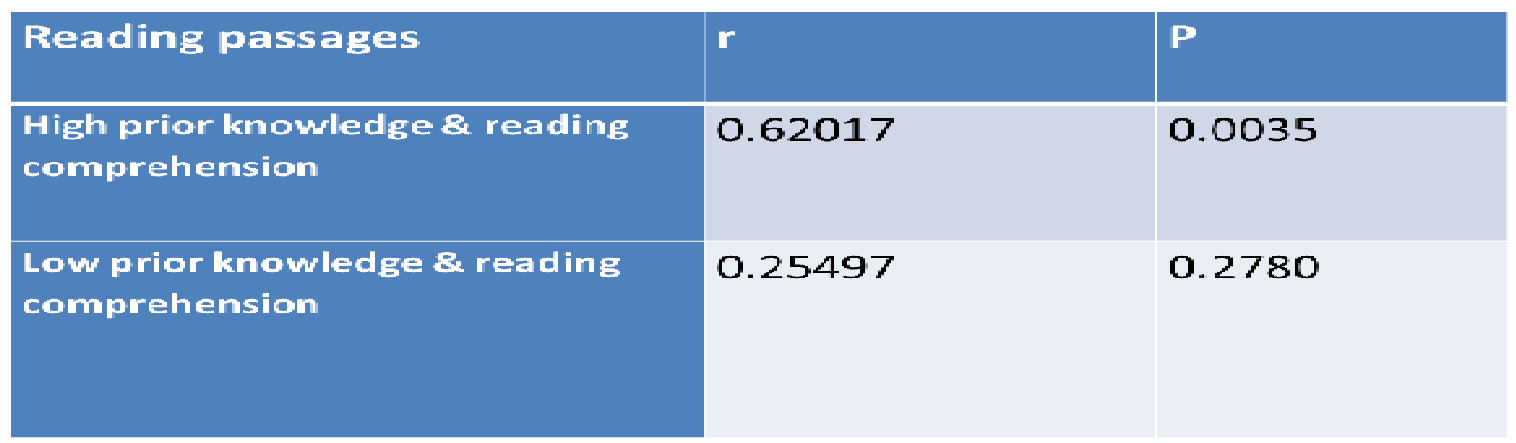

Table 2 shows the relationship between high prior knowledge and reading comprehension on one hand, and the relationship between the low prior knowledge and reading comprehensions. That is to address the objectives mentioned above.

SAS was used to analyze the results of the subjects. This result is significant at the $p=0.05$ level. There was a significant positive correlation between high prior knowledge and reading comprehension. $\mathrm{P}$ was at $(0.0035)$ which indicates high positive significance. The result shows that the higher prior knowledge is, the higher reading comprehension is.

To address the second objective of the study which was whether low prior knowledge affects reading comprehension or not. Correlation analysis was carried out. The result statistically did not show significant relationship. There is a relationship but not significant. $\mathrm{P}$ was at $(0.2780)$ which indicates insignificant relationship.

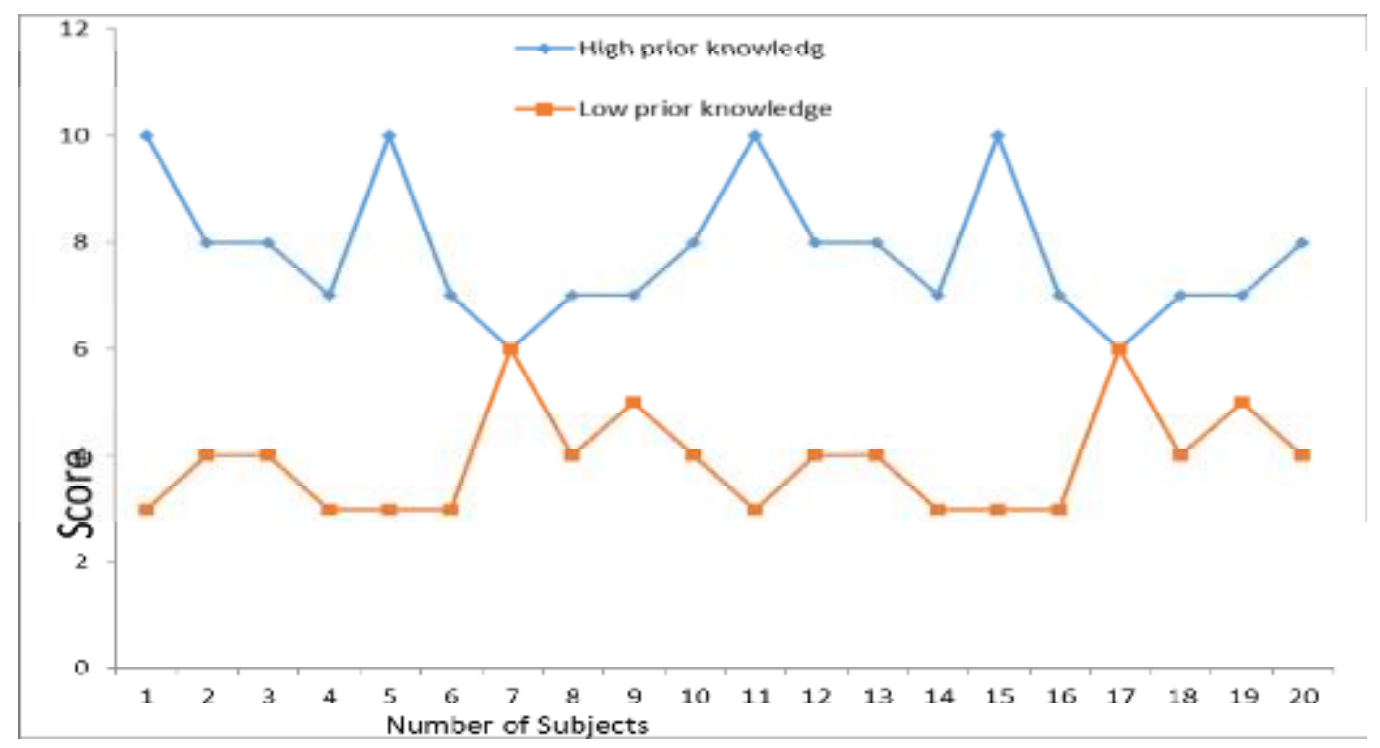

Figure 4. Relationship between the scores of the High prior knowledge passage, and the low prior knowledge passage

Figure 4 compares the scores of the high prior knowledge passage, and the low prior knowledge passage. As it is apparent there is a wide gap between the scores of student in the reading passage with high prior knowledge, and the 
one with low prior knowledge. Students scored significantly better in the passage with high prior knowledge. T-test showed that there is a strong negative correlation between the scores of the two passages.( $\mathrm{r}$ was at -0.6110$)$.

\subsection{Discussion}

The main aim of the present study was to explore the relationship between prior knowledge and reading comprehension, to know whether prior knowledge affects reading comprehension or not. Along with the literature on reading comprehension, once more it has been demonstrated the complexity of this process.

According to the data, in the passage with high prior knowledge, students performed much better. This agrees with the schema theory which highlights the importance of prior knowledge. According to Plastina (1997), in both cases (high and low prior knowledge), the individual is piecing bits of knowledge together, attempting to make sense of them. It follows that the main features of schemata are flexibility and creativity. Schemata are flexible in that they undergo a cyclic process within which changes are brought about actively and economically, i.e., information is stored in memory and provided when needed with the least amount of effort. They are creative in that they can be used to represent all types of experiences and knowledge, i. e.; they are specific to what is being perceived.

Carrell and Floyd (1989) maintain that the ESL teacher must provide the student with

appropriate schemata s/he is lacking, and must also teach the student how to build bridges between existing knowledge and new knowledge. Accordingly, the building of bridges between a student's existing knowledge and new knowledge needed for text comprehension. A number of organized pre-reading approaches and methods have been proposed in the literature for facilitating reading through activation of background knowledge.

However, the results of this study could be enriched by including other variables considered by many scholars as fundamental in reading comprehension: decoding, working memory, motivation, reading experience, knowledge of text structure, which could also mediate the relationship between prior knowledge and reading performance. Thus, the effect of prior knowledge should be controlled by varying also the text structures across the different school subjects.

\section{Conclusion}

This study showed high significant relationship between prior knowledge and reading comprehension. It showed that having high prior knowledge results in high reading comprehension. Although the study showed strong relationship between high prior knowledge and reading comprehension, it showed weak relationship between prior knowledge and reading comprehension. It shows that it is important to have high prior knowledge to achieve high performance in reading comprehension. On the other hand not having such high prior knowledge does not imply poor performance if the reader is highly competent in the language.

Consequently, I recommend that teachers activate the correct prior knowledge and correct the incorrect background information. Further studies also can be done on a larger scale of students to find more concrete results.

\section{References}

Adams, M. and Bruce, B. (1980) Background knowledge and reading comprehension (reading education report no. 13). Urbana, IL: University of Illinois, center for the study of reading.

Anderson, R.C; Spiro, R.J; \& Anderson, M.C (1978) Schemata as scaffolding for the representation of information in connected discourse. American Educational Research Journal, 15 (3), 433-440.

Arbib, M. (1992). Schema theory. Encyclopedia of artificial intelligence.

Baldwin, R., Peleg-Bruckner, Z., \& McClintock, A. (1985). Effects of topic interest and prior knowledge on reading comprehension. Reading research quarterly, 20(4), 497-504.

Bransford, J. D. And johnson, M. K. (1973) Consideration of some Problems of Comprehension. In w. G. Chase (ed.), Verbal Information Processing. New York: Academic Press.

Carrell, P. L. (1987).Content and formal schemata in ESL reading. TESOL Quarterly, 21, 461-481.

Carrell, P., and P. Floyd ( 1989). Effects on ESL reading of teaching cultural content schemata. Language Learning, 37, pp. 88-108.

Carrell, P. L., \& Wise, T. E. (1998). the Relationship Between Prior Knowledge and Topic Interest in Second Language Reading. Studies in Second Language Acquisition, 20(03), 285-309.

Chen, C. (2008). The effect of background knowledge and previews on elementary native mandarin-speaking English language learner's reading comprehension.

Dochy, F. (1994). Prior knowledge in learning. In T. Husen \& T.N. Postlethewaite (Eds.), International Encyclopedia of Education (Second edition, pp. 4698-4702). Oxford/New York: Pergamon Press.

Dochy, F. Segers, M., \& Buehl, M.M. (1999). The relationship between assessment practices and outcomes of studies: The case of research on prior knowledge. Review of Educational Research, 69 (2), 145-186.

Gilakjani, A. P., \& Ahmadi, S. M. (2011). The Relationship between L2 Reading Comprehension and Schema Theory: A Matter of Text Familiarity, 1(2).

Johnston, P. (1984). Prior knowledge and reading comprehension test bias. Reading Research Quarterly, 19(2), 219239. 
Hudson, T. (2007). Teaching second language reading. Oxford University Press.

Kintsch, W., Kozminsky,E., Streby, J., Mckoon, G., and Keena, J. M. (1975, 14, 190-214) Comprehension and recall as a function of content variables. Journal of Verbal Learning and Verbal Behavior.

Li, X., Wu, J., \& Wang, W. (2007). Analysis of schema theory and its influence on reading. US-China foreign language, 5(11), 18-21.

McNeil, L. (2011). Investigating the contributions of background knowledge and reading comprehension strategies to L2 reading comprehension: an exploratory study. Reading and Writing.

Nassaji, H. (2002). Schema Theory and Knowledge-Based Processes in Second Language Reading Comprehension : A Need for Alternative Perspectives, (June), 439-481.

Ozuru, Y., Dempsey, K., \& Mcnamara, D. S. (2009). Prior knowledge, reading skill, and text cohesion in the comprehension of science texts. Learning and Instruction, 19(3), 228-242.

Peregoy, S.F; \& Boyle, O.F. (2000). English learners reading English: What we know, what we need to know. Theory into Practice, 39(4), 237-247.

Plastina, A.F. (1997). MA in Linguistics (TESOL) University of Surrey, U.K. Unpublished.

Shapiro, A. M. (2004). How Including Prior Knowledge As a Subject Variable May Change Outcomes of Learning Research. American Educational Research Journal.

Therrien, W. J. (2004). Fluency and Comprehension Gains as a Result of Repeated Reading: A Meta-Analysis. Remedial and Special Education.

Two, C. (2000). ACTIVITY. In Defining Comprehension (pp. 11-17).

Walraven, A. M., Reitsma, P., \& Kappers, E. J. (1993). Instruction in strategies for reading comprehension to poor readers. Pedagogische Studieen, 70, 298-308.

Willingham, D.T (2007). How we learn ask the cognitive scientist. The usefulness of brief instruction in reading comprehension strategies.[ Electronic Version] American Educator (Winter). 